\section{Correction: Vol. 22, No. 4}

The authors of Microevolution of Monophasic Salmonella Typhimurium during Epidemic, United Kingdom, 2005-2010 (L. Petrovska al.) have provided the following Addendum: "It has come to the authors' attention that the designation 'Salmonella Genetic Island 3 (SGI-3)' has been previously assigned to a $31-\mathrm{kb}$ genomic island in a strain of Salmonella Mississippi (http://dx.doi.org/10.1371/journal.pone.0041247). To avoid confusion in the literature, we propose that the SGI-3 referred in our manuscript be designated SGI-4 in future reference." In addition, some of the accession numbers listed in online Technical Appendix 1 were incorrect, and funding sources and author contact information for the article have also been updated. The article has been corrected online (http://wwwnc.cdc.gov/eid/ article/22/4/15-0531_article).

\section{Correction: Vol. 22, No. 6}

The increase in monkeypox cases in the Bokungu Health Zone of the Democratic Republic of the Congo during the second half of 2013 should have been listed as $>600 \%$ in the abstract of the article in Extended Human-toHuman Transmission during a Monkeypox Outbreak in the Democratic Republic of the Congo (L.D. Nolen al.). The article has been corrected online (http://wwwnc.cdc.gov/ eid/article/22/6/15-0579_article).

\section{Correction: Vol. 22, No. 6}

The name of Wenqing Zhang was misspelled in the acknowledgments of Improved Global Capacity for Influenza Surve (L.S. Polansky et al.). The article has been corrected online (http://wwwnc.cdc.gov/eid/article/22/6/15-1521_ article).

\section{Correction: Vol. 22, No. 6}

The descriptions of pneumonia diagnoses and hospitalizations were unclear in Changes in Childhood Pneumonia Hospitalizations by Race and Sex Associated with Pneumococcal Conjugate Vaccines (A.D. Wiese al.). The article has been corrected online (http://wwwnc.cdc. gov/eid/article/22/6/15-2023_article).

\section{August 2016: Parasitology Including}

- Coinfections with Visceral Pentastomiasis, Democratic Republic of the Congo

- Probable Rabies Virus Transmission through Organ Transplantation, China, 2015

- Microgeographic Heterogeneity of Border Malaria During Elimination Phase, Yunnan Province, China

- Virulence and Evolution of West Nile Virus, Australia, 1960-2012

- Phylogeographic Evidence for Two Genetically Distinct Zoonotic Plasmodium knowlesi Parasites, Malaysia

- Hemolysis after Oral Artemisinin Combination Therapy for Uncomplicated Plasmodium falciparum Malaria

- Middle East Respiratory Syndrome Coronavirus Transmission in Extended Family, Saudi Arabia, 2014

- Exposure-Specific and Age-Specific Attack Rates for Ebola Virus Disease in Ebola-Affected Households, Sierra Leone

- Outbreak of Achromobacter xylosoxidans and Ochrobactrum anthropi Infections after Prostate Biopsies, France, 2014

- Possible Role of Fish and Frogs as Paratenic Hosts of Dracunculus medinensis, Chad

- Human Babesiosis, Bolivia, 2013

- Importation of Hybrid Human-Associated Trypanosoma cruzi Strains of Southern South American Origin, Colombia

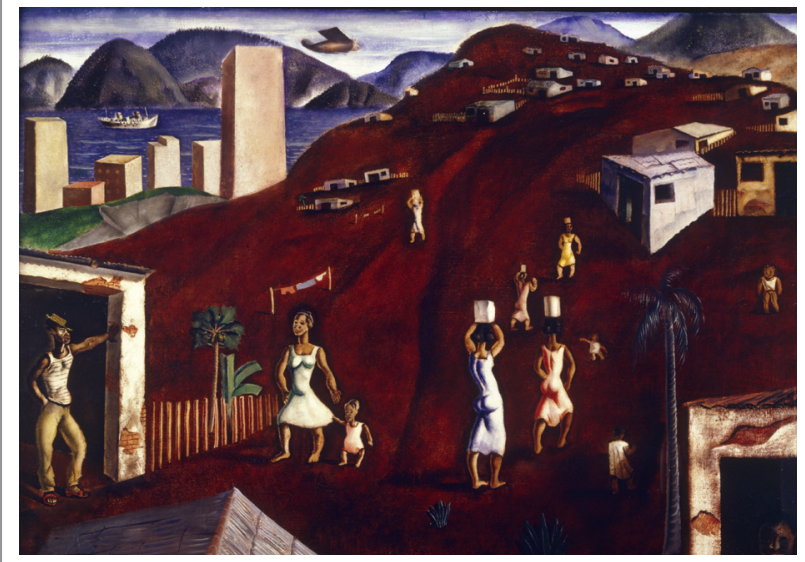

http://wwwnc.cdc.gov/eid/articles/ issue $/ 22 / 08 /$ table-of-contents

\section{EMERGING}

INFECTIOUS DISEASES 